\title{
Combination of antiangiogenic therapy using the mTOR-inhibitor everolimus and low-dose chemotherapy for locally advanced and/or metastatic pancreatic cancer: a dose-finding study
}

\author{
Mareile Joka ${ }^{\mathrm{a}}$, Stefan Boeck ${ }^{\mathrm{b}}$, Christoph J. Zech ${ }^{\mathrm{c}, \mathrm{h}}$, Thomas Seufferlein ${ }^{\mathrm{d}}$, \\ Goetz von Wichert ${ }^{\mathrm{d}}$, Thomas Licht ${ }^{\mathrm{e}}$, Annekatrin Krause ${ }^{\mathrm{f}}$, Karl-Walter Jauch ${ }^{\mathrm{a}}$, \\ Volker Heinemann ${ }^{\mathrm{b}}$ and Christiane J. Bruns ${ }^{\mathrm{g}}$
}

Pancreatic adenocarcinomas are associated with a poor survival prognosis. Besides curative surgical resection, only limited therapies with modest impact are available. New evidence suggests that the mammalian target of rapamycin pathway may be involved in the pathogenesis of neuroendocrine tumors, and breast and renal cell cancer. The phase I study described here was therefore designed to determine the maximum tolerated dose (MTD) and doselimiting toxicity (DLT) of escalating doses of the mammalian target of rapamycin inhibitor everolimus in combination with gemcitabine in patients with advanced pancreatic cancer. Eligible patients had histologically confirmed locally advanced and/or metastatic pancreatic carcinoma and were administered $5 \mathrm{mg}$ everolimus every second day (cohort 1 , 2,3 ) or 5 mg daily (cohort 4,5 ) in combination with escalating low-dose gemcitabine. It was found that if two patients showed DLTs, MTD was reached and gemcitabine dose escalation was stopped at this level. Twenty-seven patients were enrolled in the study (cohort 1: $n=3$; cohort 2: $n=4$; cohort 3: $n=6$; cohort 4: $n=7$; cohort $5: n=7$ ) and received a maximum $600 \mathrm{mg}$ gemcitabine/week. In cohort
5, two of the six patients experienced DLTs (grade 3 liver toxicity lasting for $>7$ days). MTD was measured as $400 \mathrm{mg} /$ $\mathrm{m}^{2} /$ week gemcitabine plus $5 \mathrm{mg} /$ day everolimus. The MTD of a low-dose gemcitabine treatment in combination with everolimus was determined and no new safety concerns were identified in patients with advanced pancreatic cancer. Anti-Cancer Drugs 25:1095-1101 (c) 2014 Wolters Kluwer Health | Lippincott Williams \& Wilkins.

Anti-Cancer Drugs 2014, 25:1095-1101

Keywords: dose finding, everolimus, gemcitabine,

locally advanced and/or metastatic pancreatic cancer, safety

aDDepartment of Surgery, ${ }^{b}$ Department of Internal Medicine III, ' Institute of Radiology, LMU, Munich, dDepartment of Internal Medicine I, University Ulm, Ulm, ${ }^{e}$ BRK Schlossbergklinik, Oberstaufen, ${ }^{f}$ Novartis Pharma GmbH, Nürnberg, 9Department of Surgery, University of Magdeburg, Magdeburg, Germany and hDepartment of Radiology and Nuclear Medicine, University Basel, Basel, Switzerland

Correspondence to Mareile Joka, MD, Department of Surgery, LMU, Marchioninistr 15, 81377 München, Germany

Tel: +49 894400 73566; fax: +49 89440076567 ;

e-mail: mareile.joka@med.uni-muenchen.de

Received 26 April 2013 Revised form accepted 10 June 2014

\section{Introduction}

Pancreatic cancer remains one of the greatest challenges in oncology. At present, pancreatic adenocarcinoma is associated with an unfavorable prognosis and poor overall survival. Surgical resection remains the only potentially curative option, but only $15-20 \%$ of patients will have resectable tumors, whereas the majority of patients have locally advanced or metastatic disease at the initial time of diagnosis [1]. During the last decade, standard treatment for patients with advanced pancreatic cancer was systemic chemotherapy with gemcitabine, with a median overall survival of about 6 months. To improve upon this modest benefit, several investigations have explored other strategies for reducing pancreatic cancer growth by administering various cytotoxic and targeted agents together with gemcitabine, or - more recently - by introducing novel combination chemotherapy regimens such as FOLFIRINOX or gemcitabine plus nabpaclitaxel [1-6].
Tumor angiogenesis is the process leading to the formation of blood vessels within a tumor and plays a key role in cancer cell survival and the development of distant metastases. Multiple preclinical studies have shown the efficacy of a broad variety of antiangiogenic compounds as antitumor agents for solid tumors; in particular, the efficacy of mammalian target of rapamycin (mTOR) inhibitors against pancreatic and colon cancer in combination with chemotherapy has been evaluated. Tumor growth and metastases of pancreatic and colon cancer were significantly inhibited by low doses of antiangiogenic therapy in combination with chemotherapy [7]. In addition, Browder and colleagues showed in animal models that low-dose chemotherapy itself acts antiangiogenically and was effective even in chemotherapyresistant solid malignancies [8-10].

Experiments with gemcitabine combined with targeted therapy such as an EGFR antibody in human umbilical endothelial cells and animal models suggest potential 
additional effects of gemcitabine on proliferating endothelial cells in vitro or tumor angiogenesis in vivo. Similar effects could be the basis of a combination therapy of gemcitabine and RAD001, which is a more downstream targeted therapy than an EGFR antibody [11]. The $\mathrm{mTOR}$ is a serine-threonine kinase, which is a member of the larger phosphatidylinositol 3-kinase (PI3K) family, and is expressed in all types of cells. The PI3K/Akt/ mTOR pathway regulates many cellular properties, including cell growth, proliferation and survival, as well as metabolism and angiogenesis. Dysregulation of this pathway is characteristic of numerous proliferative disorders including cancer because of the fact that many tumors carry gene mutations that result in the hyperactivation of phosphatidylinositol 3-kinase/protein kinase $\mathrm{B}$ and mTOR signaling pathways. Overall, these data point to $\mathrm{mTOR}$ as a relevant target for antitumor treatment [12-15].

Everolimus (RAD001; Afinitor) is a novel macrolide derivative of rapamycin formulated for oral administration, which is being developed as an antiproliferative drug with applications either as an immunosuppressant or as an anticancer agent, which acts by selectively inhibiting mTOR downstream signaling events [16,17]. In oncology, experiences with everolimus are based on preclinical and clinical studies in renal cell cancer, neuroendocrine tumors, and breast cancer, and showed good efficacy of everolimus as a novel antiproliferative drug [16-22]. Within the recently reported phase III trial BOLERO-2, the progression-free survival in postmenopausal hormone-receptor-positive advanced breast cancer patients treated with a combination of everolimus and exemestane was also significantly improved (nearly 11 vs. 4 months) [23].

On the basis of currently available results from pharmacokinetic drug-to-drug interaction studies, gemcitabine did not alter everolimus pharmacokinetics to a clinically relevant extent. Coadministration of everolimus did not influence the pharmacokinetics of gemcitabine, imatinib, or letrozole (Novartis, data on file). However, preliminary data from Pacey et al. [24] showed that combination therapy with gemcitabine $600 \mathrm{mg} / \mathrm{m}^{2} /$ week together with everolimus $20 \mathrm{mg} /$ week produced significant hematological toxicity (grade 4 neutropenia and grade 3 thrombocytopenia) in patients with solid tumors.

The aim of this open-label, multicenter study was thus to investigate whether patients with locally advanced and/or

Table 1 Dosing details of cohorts 1-5

\begin{tabular}{|c|c|c|c|}
\hline & Patients $(N)$ & Everolimus & Gemcitabine $\left(\mathrm{mg} / \mathrm{m}^{2} /\right.$ week $)$ \\
\hline Cohort 1 & 3 & $5 \mathrm{mg} / \mathrm{second}$ day & 400 \\
\hline Cohort 2 & 4 & $5 \mathrm{mg} / \mathrm{second}$ day & 500 \\
\hline Cohort 3 & 6 & $5 \mathrm{mg} / \mathrm{second}$ day & 600 \\
\hline Cohort 4 & 7 & $5 \mathrm{mg} /$ day & 400 \\
\hline Cohort 5 & 7 & $5 \mathrm{mg} /$ day & 500 \\
\hline
\end{tabular}

metastatic pancreatic cancer can be treated safely with a combination of everolimus and low-dose gemcitabine chemotherapy. The study was designed as a phase I dose-finding trial to evaluate the maximum tolerated dose (MTD) of this combination treatment.

\section{Patients and methods Patient eligibility}

Adult patients with histologically confirmed locally advanced or metastatic pancreatic adenocarcinoma were eligible for study enrollment. Further key inclusion criteria were as follows: adequate bone marrow, liver, and renal function on RAD001 treatment; at least one measurable lesion [longest diameter $\geq 20 \mathrm{~mm}$ on conventional computed tomography (CT) or MRI scan; $\geq 10 \mathrm{~mm}$ on spiral CT] according to the RECIST criteria (version 1.0) that has not been irradiated previously; at least 4 or 2 weeks' time since previous major/minor surgery and recovery, completion of radiation, or completion of all previous systemic anticancer therapy. Eligible patients must have an ECOG performance status of 0-2.

Individuals were not eligible for study enrollment if there was documented intolerance to everolimus or gemcitabine, a history of another malignancy within 5 years before study enrollment, or if patients had a marked impairment in gastrointestinal function or gastrointestinal disease that may significantly alter the absorption of RAD001. Furthermore, previous treatment with an mTOR inhibitor or with gemcitabine was not allowed (except adjuvant treatment with gemcitabine, which had to be completed $\geq 3$ months before study entry). The clinical trial was conducted in accordance with the Declaration of Helsinki as well as local laws and regulations and with the approval of an independent ethics committee (approved protocol NCT00560963), and all patients provided written informed consent before study enrollment.

\section{Study design and treatment}

The study was designed as a prospective, open-label, multicenter phase I study of continuous doses of everolimus (5 mg) every second day (cohorts 1,2 , and 3 ) or every day (cohorts 4 and 5) in combination with escalating low-dose gemcitabine $\left(400,500\right.$, and $\left.600 \mathrm{mg} / \mathrm{m}^{2}\right)$ administered as a weekly intravenous infusion over 30 min (Table 1). The primary objective was to determine the MTD of the combination treatment. At least three patients were enrolled per cohort. If $1 / 3$ patients experienced dose-limiting toxicity (DLT), the cohort was expanded to 6 . If at least $2 / 3$ patients had DLT, dose escalation was stopped. For extended cohorts, dose escalation was allowed if $1 / 6$ patients had DLT. Dose escalation was stopped if DLT were documented for at least 2/6 patients. Determination of MTD was based on the DLT rate. One treatment cycle was defined as study drug administration for 28 days. All patients were to be 
followed for a minimum of 8 weeks following the start of study treatment before escalating to the next level. Patients whose therapy with gemcitabine and RAD001 was safe were offered to continue the therapy until disease progression. DLTs were defined as treatmentrelated adverse events (AEs) of at least grade 3 according to CTCAE (common terminology criteria for adverse events) version 3.0; DLTs were listed individually by dose cohort.

The secondary objectives of the study were to characterize the safety and tolerability of everolimus in combination with gemcitabine including acute and chronic toxicities and to evaluate preliminary efficacy defined as the overall response rate [complete response (CR) and partial response (PR)] according to RECIST, version 1.0 .

\section{Study assessments}

During study participation, monitoring of vital signs, physical examination, assessment of ECOG status, and laboratory assessments were performed at every weekly visit. To determine the pharmacology data, serum everolimus samples were taken at visit 3 to the end-of-study visit (or premature discontinuation visit).

For the safety assessments, the rate of $\mathrm{AE}$ and serious adverse events (SAE) as well as the number of laboratory values beyond predetermined ranges were monitored and recorded at every visit.

Disease status was assessed by CT or contrast MRI scans and tumor evaluation according to RECIST (version 1.0), as well as evaluation of tumor markers (CEA, CA19-9) at the screening and at the end-of-study visit (or premature discontinuation visit).

Table 2 Patient characteristics $(N=27)$

\begin{tabular}{lcccccc}
\hline & $\begin{array}{c}\text { Total } \\
\text { Safety population }\end{array}$ & $\begin{array}{c}\text { Cohort } \\
1\end{array}$ & $\begin{array}{c}\text { Cohort } \\
2\end{array}$ & $\begin{array}{c}\text { Cohort } \\
3\end{array}$ & $\begin{array}{c}\text { Cohort } \\
4\end{array}$ & $\begin{array}{c}\text { Cohort } \\
5\end{array}$ \\
$(N=3)$ & $(N=4)$ & $(N=6)$ & $(N=7)$ & $(N=7)$ \\
\hline Age (years) & & & & & & \\
$\quad$ Minimum & 46 & 46 & 53 & 64 & 55 & 57 \\
$\quad$ Median & 67 & 67 & 67 & 70 & 67 & 63 \\
$\quad$ Maximum & 83 & 70 & 76 & 73 & 83 & 80 \\
Sex (n) & & & & & & \\
$\quad$ Male & 17 & 3 & 2 & 3 & 7 & 2 \\
Female & 10 & 0 & 2 & 3 & 0 & 5 \\
Race $(n)$ & & & & & & \\
White & 27 & 3 & 4 & 6 & 7 & 7 \\
Metastasis [n (\%)] & & & & & & \\
No & $7(26)$ & $1(33)$ & $0(0)$ & $2(33)$ & $2(29)$ & $2(29)$ \\
Yes & $20(74)$ & $2(67)$ & $4(100)$ & $4(67)$ & $5(71)$ & $5(71)$ \\
$\quad$ Peritoneum & $4(15)$ & $0(0)$ & $0(0)$ & $0(0)$ & $4(57)$ & $0(0)$ \\
$\quad$ Liver & $13(48)$ & $2(67)$ & $3(75)$ & $2(33)$ & $2(29)$ & $4(57)$ \\
$\quad$ Lungs & $2(7)$ & $0(0)$ & $0(0)$ & $0(0)$ & $2(59)$ & $0(0)$ \\
$\quad$ Lymph nodes & $10(37)$ & $2(67)$ & $1(25)$ & $3(50)$ & $4(57)$ & $0(0)$ \\
$\quad$ Other & $10(37)$ & $2(67)$ & $1(25)$ & $3(50)$ & $4(57)$ & $0(0)$ \\
ECOG score 0 & 13 & 3 & 3 & 3 & 1 & 3 \\
ECOG score 1 & 12 & 0 & 0 & 3 & 6 & 3 \\
ECOG score 2 & 2 & 0 & 1 & 0 & 0 & 1 \\
\hline & & & & & & \\
\hline
\end{tabular}

\section{Statistical analysis}

All patients who received at least one dose of everolimus and/or gemcitabine and had at least one postbaseline safety assessment were included in the safety population. Furthermore, an MTD-determining population was defined: if a patient fulfilled the minimum study safety requirements for cycle 1 and if the patient either experienced DLT during cycle 1 or had received at least 21 days of both everolimus and gemcitabine, the patient was observed for at least 28 days following the first dose, and if all the required safety evaluations had been completed, the patient was included in this population. For further analysis, data from all four participating centers were pooled and summarized. Demographic and baseline characteristics (including disease characteristics), efficacy observations and measurements as well as safety observations and measurements were therefore included in the analysis.

Descriptive statistics such as mean, standard deviation, minimum, median, and maximum were presented for continuous variables.

\section{Results \\ Patient characteristics}

All 27 patients with histologically confirmed advanced pancreatic adenocarcinoma were screened at four study centers and included in one of the five study cohorts. Patient baseline characteristics as well as disease history are listed in Table 2. The patients' median age was 67 years (range $46-83$ years). The majority of patients in cohorts 1,3 , and 4 were more than 65 years, whereas the reverse age distribution was observed for patients in cohort 5. In cohort 2, all four age groups were equally frequent. Cohorts 1 and 4 included only male patients, whereas the majority of patients in cohort 5 were female. An equal percentage of patients were male and female in cohorts 2 and 3 . At screening, 13 patients had an ECOG score of 0,12 a score of 1 , and the two remaining study participants had an ECOG score of 2; 20 patients had metastatic and seven patients had locally advanced disease at study entry. All 27 treated patients were included in the safety study population and of those, 23 patients were included in the MTD population. The remaining four patients were treated with study drugs for less than 8 weeks $(3,4,14$, and 17 days, respectively) and were thus not included in the MTD population.

\section{Study treatment}

Cohort design and dosing details are listed in Tables 3 and 4: the overall median daily dose of everolimus was $3.9 \mathrm{mg} /$ day. The median daily doses of everolimus were higher in cohorts 1,4 , and $5(4.3,5.0$, and $4.0 \mathrm{mg} /$ day, respectively) than in cohorts 2 and $3(3.7$ and $2.6 \mathrm{mg} /$ day, respectively) for the safety population. The median everolimus exposure time in the MTD-determining population was 49 days (range 0-63 days). Dose 
Table 3 Patient disposition $(N=27)$

\begin{tabular}{|c|c|c|c|c|}
\hline & Screened & Treated & Discontinued & Completed \\
\hline \multicolumn{5}{|l|}{ Number of patients (\%) } \\
\hline All cohorts $(N=27)$ & 27 & 27 & 6 & 21 \\
\hline Cohort $1(N=3)$ & 3 & 3 & 0 & 3 \\
\hline Cohort $2(N=4)$ & 4 & 4 & 1 & 3 \\
\hline Cohort $3(N=6)$ & 6 & 6 & 0 & 6 \\
\hline Cohort $4(N=7)$ & 7 & 7 & 3 & 4 \\
\hline Cohort $5(N=7)$ & 7 & 7 & 2 & 5 \\
\hline \multicolumn{5}{|c|}{ Main reason for discontinuation $[n(\%)]$} \\
\hline \multicolumn{3}{|c|}{ Adverse event(s) } & \multicolumn{2}{|l|}{$3(11)$} \\
\hline \multicolumn{3}{|c|}{ Patient withdrew consent } & \multicolumn{2}{|l|}{$1(4)$} \\
\hline \multicolumn{3}{|l|}{ Lost to follow-up } & \multicolumn{2}{|l|}{$1(4)$} \\
\hline \multicolumn{3}{|l|}{ Death } & \multicolumn{2}{|l|}{$1(4)$} \\
\hline
\end{tabular}

changes for everolimus were documented for about $70 \%$ of patients. Most of these had one to four changes (Table 5). Reasons for the vast majority of changes in both the safety and the MTD-determining population were as foreseen by the protocol (e.g. protocol predefined dose adjustment of everolimus on the basis of serum levels).

A study amendment (issued after the inclusion of $3 / 27$ patients) allowed RAD001 dose adjustments only for toxicity and not anymore with regard to serum level. A subsequent amendment (issued after $11 / 27$ patients) introduced two further cohorts (cohorts 4 and 5) with RAD001 $5 \mathrm{mg}$ daily in combination with gemcitabine when further experience on the use of RAD001 had indicated that the combination is safe and the MTD had not been reached so far.

For about one-quarter of patients in the safety population, an $\mathrm{AE}$ or a laboratory or test abnormality was the reason for the dose change. A dosing error occurred in one patient (Table 5). Across all cohorts, the median daily dose of gemcitabine relative to body surface area was $61.5 \mathrm{mg} / \mathrm{day} / \mathrm{m}^{2}$ (range 46.5-400) in the MTDdetermining population (Table 4). More than $80 \%$ of patients had gemcitabine dose changes. Most patients
Table 5 Dose changes for everolimus and gemcitabine (safety population)

\begin{tabular}{lcc}
\hline Treatment & Everolimus $[n(\%)]$ & Gemcitabine \\
\hline Number of patients & $27(100)$ & $27(100)$ \\
Number of changes per patient & & \\
0 & $8(30)$ & $5(19)$ \\
1 & $3(11)$ & $4(15)$ \\
2 & $3(11)$ & $4(15)$ \\
3 & $3(11)$ & $4(15)$ \\
4 & $3(11)$ & $6(22)$ \\
5 & - & $2(7)$ \\
6 & $1(4)$ & $2(7)$ \\
7 & $2(7)$ & - \\
9 & $2(7)$ & - \\
14 & $1(4)$ & - \\
16 & $1(4)$ & $70(100)$ \\
Number of changes & $98(100)$ & $37(53)$ \\
Reasons for dose/change & $73(74)$ & $30(43)$ \\
As per protocol & $24(24)$ & $0(0)$ \\
Adverse event/laboratory or test & & $3(4)$ \\
abnormality & $1(1)$ & $0(0)$ \\
Dosing error & &
\end{tabular}

had one to four changes. Slightly more than half of the dose changes were as per protocol and more than $40 \%$ of the dose changes were because of an AE or laboratory or test abnormality (Table 5). Patients were exposed to gemcitabine for a median of 50 days (range 1-64) in the MTD-determining population (Table 4).

\section{Safety and efficacy evaluation}

Of the 27 patients treated, 21 completed the study. Six patients were withdrawn because of AEs (three), withdrawn consent (one), loss to follow-up (one), and death (one) (Table 3). AEs leading to discontinuation were reported as moderate worsening of general condition (no relation to study drug), severe neutropenia (study drug related), and moderate to severe laboratory changes, including drug-related increase in alanine aminotransferase, aspartate aminotransferase, and bilirubin. In total, 25 of 27 patients (93\%) reported at least one AE.

Table 4 Treatment administration of everolimus and gemcitabine by cohorts (maximum tolerated dose-determining population)

\begin{tabular}{|c|c|c|c|c|c|c|}
\hline MTD-determining population & Cohort $1(N=3)$ & Cohort $2(N=3)$ & Cohort $3(N=6)$ & Cohort $4(N=5)$ & Cohort $5(N=6)$ & All $(N=23)$ \\
\hline Everolimus dose (mg/day) & $5 \mathrm{mg} / \mathrm{second}$ day & $5 \mathrm{mg} / \mathrm{second}$ day & $5 \mathrm{mg} / \mathrm{second}$ day & $5 \mathrm{mg} /$ day & $5 \mathrm{mg} /$ day & \\
\hline Gemcitabine dose $\left(\mathrm{mg} / \mathrm{m}^{2} /\right.$ week $)$ & 400 & 500 & 600 & 400 & 500 & \\
\hline \multicolumn{7}{|l|}{ Daily dose of everolimus (mg/day) } \\
\hline Evaluable patients $(N)$ & 3 & 3 & 6 & 5 & 6 & 23 \\
\hline Median & 4.3 & 3.7 & 2.6 & 5.0 & 4.0 & 3.9 \\
\hline Range & $3.5-4.5$ & $1.9-3.9$ & $1.8-2.6$ & $4.3-5.1$ & $2.3-5.0$ & $1.8-5.1$ \\
\hline \multicolumn{7}{|l|}{ Everolimus exposure time (days) } \\
\hline Evaluable patients $(N)$ & 3 & 3 & 6 & 5 & 6 & 23 \\
\hline Median & 49 & 35 & 49 & 50 & 46 & 49 \\
\hline Range & $49-63$ & $34-49$ & $49-57$ & $4-50$ & $23-50$ & $4-63$ \\
\hline \multicolumn{7}{|c|}{ Daily dose of gemcitabine $\left(\mathrm{mg} /\right.$ day $\left./ \mathrm{m}^{2}\right)$} \\
\hline Evaluable patients $(N)$ & 3 & 3 & 6 & 5 & 6 & 23 \\
\hline Median & 55.6 & 67.7 & 84.9 & 56.0 & 62.6 & 61.5 \\
\hline Range & $46.5-56.3$ & $58.1-80.1$ & $49.8-100$ & $48-400$ & $50-81.9$ & $46.5-400$ \\
\hline \multicolumn{7}{|l|}{ Gemcitabine exposure time (days) } \\
\hline Evaluable patients $(N)$ & 3 & 3 & 6 & 5 & 6 & 23 \\
\hline Median & 43 & 43 & 46 & 50 & 50 & 50 \\
\hline Range & $36-64$ & $29-50$ & $36-50$ & $1-50$ & $47-50$ & $1-64$ \\
\hline
\end{tabular}

MTD, maximum tolerated dose. 
In cohorts 3, 4, and 5, every patient reported at least one $\mathrm{AE}$, whereas in cohorts 1 and 2, one of the patients reported no AEs. Overall, thrombocytopenia was the most frequent $\mathrm{AE}$, followed by leukopenia and nausea. The majority of patients experienced AEs with suspected relation to the study drug $(81 \%)$. Furthermore, 11 patients (41\%) experienced at least one SAE. Details of study drug-related AEs are listed as per cohort and CTCAE version 3.0 grading in Table 6. Two patients (both in cohort 4) died during the study (unrelated to study drug) and one patient died 8 days after study termination. Of the AEs reported, three events (two AEs,

Table 6 Number of patients with suspected drug-related adverse events per cohort (safety population)

\begin{tabular}{|c|c|c|c|c|c|c|c|c|c|c|c|c|}
\hline \multirow{3}{*}{$\begin{array}{l}\text { Number of patients with any drug-related AEs } \\
\text { CTC grade }\end{array}$} & \multirow{2}{*}{\multicolumn{2}{|c|}{$\frac{\text { Cohort } 1(N=3)}{2}$}} & \multirow{2}{*}{\multicolumn{2}{|c|}{$\frac{\text { Cohort } 2(N=4)}{2}$}} & \multirow{2}{*}{\multicolumn{2}{|c|}{$\frac{\text { Cohort } 3(N=6)}{5}$}} & \multirow{2}{*}{\multicolumn{2}{|c|}{$\frac{\text { Cohort } 4(N=7)}{6}$}} & \multirow{2}{*}{\multicolumn{2}{|c|}{$\frac{\text { Cohort } 5(N=7)}{7}$}} & \multirow{2}{*}{\multicolumn{2}{|c|}{$\begin{array}{l}\text { All }(N=27) \\
22(81 \%)\end{array}$}} \\
\hline & & & & & & & & & & & & \\
\hline & $1-2$ & $3-4$ & $1-2$ & $3-4$ & $1-2$ & $3-4$ & $1-2$ & $3-4$ & $1-2$ & $3-4$ & $1-2$ & $3-4$ \\
\hline \multicolumn{13}{|l|}{ Blood and lymphatic system disorder } \\
\hline Anemia & & & & & & & & & 1 & & 1 & \\
\hline Granulocytopenia & & & & & & & 1 & & & & 1 & \\
\hline Leukopenia & 1 & & 1 & & 4 & & 3 & & & & 9 & \\
\hline Lymphopenia & & & & & & & 2 & & & & 2 & \\
\hline Neutropenia & & & & & & & & 3 & & & & 3 \\
\hline Thrombocytopenia & 2 & & 2 & & 3 & & 3 & & 4 & 2 & 14 & 2 \\
\hline White blood cell count decreased & & & & & & & & & 1 & & 1 & \\
\hline \multicolumn{13}{|l|}{ Cardiac disorders } \\
\hline Angina pectoris & 1 & & & & & & & & & & 1 & \\
\hline \multicolumn{13}{|l|}{ Gastrointestinal disorder } \\
\hline Abdominal pain & 1 & & & & & & & & & & 1 & \\
\hline Diarrhea & & & & & 1 & & 1 & & 1 & & 3 & \\
\hline Dry mouth & & & & & & & 1 & & & & 1 & \\
\hline Dry lips & & & & & & & 1 & & & & 1 & \\
\hline Nausea & & & & & 1 & & 3 & & 2 & & 6 & \\
\hline Periodontitis & & & & & 1 & & & & & & 1 & \\
\hline Vomiting & & & & & & & 1 & & & & 1 & \\
\hline \multicolumn{13}{|l|}{ General disorders } \\
\hline Chills & & & & & & & & & 1 & & 1 & \\
\hline Fatigue & & & & & 1 & & & & 1 & & 2 & \\
\hline Edema & & & & & 2 & & & & & & 2 & \\
\hline \multicolumn{13}{|l|}{ Infections/infestations } \\
\hline Biliary tract infection & & & & & 1 & & & & & & 1 & \\
\hline Escherichia bacteremia & 1 & & & & & & & & & & 1 & \\
\hline Eyelid infection & & & & & 1 & & & & & & 1 & \\
\hline Infection & & & & & 1 & & & & & & 1 & \\
\hline Oral infection & & & & & 2 & & & & & & 2 & \\
\hline Tinea pedis & & & & & & & & & 1 & & 1 & \\
\hline Urinary tract infection & & & & & 2 & & & & 1 & & 3 & \\
\hline Laboratory investigations & & & & & & & & & & & & \\
\hline Alanine aminotransferase increased & & & & & & & & & & 1 & & 1 \\
\hline Aspartate aminotransferase increased & & & & & & & & & 1 & & 1 & \\
\hline Blood alkaline phosphatase increased & & & & & & & 1 & & & 1 & 1 & 1 \\
\hline Blood bilirubin increased & & & & & & & & & & 1 & & 1 \\
\hline Blood cholesterol increased & & & & & & & & & 1 & & 1 & \\
\hline$\gamma$-Glutamyltransferase increased & & & & & & & & & & 1 & & 1 \\
\hline Hepatic enzyme increased & & & & & & & & & & 1 & & 1 \\
\hline Lipase increased & & & & & & & & & 1 & & 1 & \\
\hline Metabolism/nutrition disorders & & & & & & & & & & & & \\
\hline Weight decreased & & & & & & & 1 & & & & 1 & \\
\hline Appetite decreased & & & & & & & 1 & & & & 1 & \\
\hline Diabetes mellitus & & & 1 & & & & & & & & 1 & \\
\hline Hyperglycemia & & & 1 & & & & & & & & 1 & \\
\hline Nervous system disorders & & & & & & & & & & & & \\
\hline Dizziness & & & & & & & & & 2 & & 2 & \\
\hline Headache & & & & & & & & & 1 & & 1 & \\
\hline Paresthesia & & & & & & & 1 & & & & 1 & \\
\hline Respiratory, thoracic, and mediastinal disorders & & & & & & & & & & & & \\
\hline Pleurisy & & & & & & & & & 1 & & 1 & \\
\hline Skin/subcutaneous tissue disorders & & & & & & & & & & & & \\
\hline Alopecia & & & & & & & & & 1 & & 1 & \\
\hline Erythema & & & & & & & 1 & & & & 1 & \\
\hline Pruritus & & & & & & & 1 & & & & 1 & \\
\hline Rash & & & & & & & 1 & & 1 & & 2 & \\
\hline Skin lesion & & & & & & & 1 & & & & 1 & \\
\hline Vascular disorders & & & & & & & & & & & & \\
\hline Hypertension & 1 & & & & & & & & & & 1 & \\
\hline
\end{tabular}

AEs, adverse events. 
Table 7 Efficacy rates and lesions according to RECIST (maximum tolerated dose-determining population)

\begin{tabular}{lc}
\hline Response & $N(\%)$ \\
\hline Total & $23(100)$ \\
Overall response rate (CR + PR) & $3(13)$ \\
Clinical benefit rate (CR + PR + SD) & $18(78)$ \\
Complete response (CR) & $0(0)$ \\
Partial response (PR) & $3(13)$ \\
Stable disease (SD) & $15(65)$ \\
Progressive disease (PD) & $3(13)$ \\
Unknown & $1(4)$ \\
Evaluation missing & $1(4)$ \\
\hline
\end{tabular}

one SAE) represented a DLT. One of these DLTs was observed in cohort 4 and two were observed in cohort 5 . For two of these, hepatic toxicity was reported with the DLT criterion being CTCAE grade 3 aspartate aminotransferase or alanine aminotransferase elevation lasting for more than 7 days. For the remaining DLT, the DLT was added as a worst case assumption: this DLT enclosed the unknown cause of death of a patient who was not a member of the MTD population in the followup data.

As per protocol, the primary efficacy variable was the overall response rate, defined as the proportion of patients in whom a CR or a PR response was observed according to RECIST (version 1.0) after 8 weeks. On the basis of RECIST, the majority of all treated patients showed stable disease (65\%); three patients each showed PR and PD. None of the patients experienced a CR; however, a clinical benefit (CR, PR, or stable disease) was documented for $78 \%$ of the patients treated (95\% CI: 56-93\%] (Table 7).

\section{Discussion}

Recent research into the molecular mechanisms of pancreatic cancer progression has led to the development of novel therapeutic approaches using targeted agents as monotherapy or in combination with gemcitabine or other chemotherapeutic agents, but so far, no clear benefit of a gemcitabine-based combination therapy has been documented in clinical trials $[1,4,5]$.

New evidence suggests that the mTOR pathway may be involved in the pathogenesis of several solid malignancies: for example, the tuberous sclerosis complex (TSG) $1 / 2$ is an inhibitor of mTOR that is present in normal neuroendocrine cells. Patients with defects in the TSC2 gene are thus known to develop islet cell tumors [17]. Recent clinical studies have documented promising efficacy and a good safety profile for everolimus as an anti-proliferative drug, when administered alone or in combination with other drugs in patients with different tumor entities such as melanoma, GIST, or breast cancer [16-23]. For pancreatic neuroendocrine tumors, two phase II and one phase III studies have been carried out so far $[17,18,22]$. In the randomized phase III study,
Yao et al. [22] compared $10 \mathrm{mg}$ everolimus daily with a placebo in patients with advanced pancreatic neuroendocrine tumors and showed significantly prolonged progression-free survival in the everolimus group associated with a low rate of severe AEs compared with placebo (11.0 vs. 4.6 months).

The majority of pancreatic ductal adenocarcinomas harbor activating mutations in KRAS, which promote cellular proliferation and survival through involvement of several downstream effectors pathways, including the PI3K/Akt/mTOR pathway, and increased activation of this pathway has been noted in approximately half of pancreatic cancers [14,25]. Furthermore, preclinical models as well as some clinical studies suggest that pancreatic cancer progression may be sensitive to antiangiogenic therapy. Browder et al. [10] documented that in animals, low-dose chemotherapy acts antiangiogenically and was effective even in solid malignancies. Combination therapy of low-dose gemcitabine together with everolimus might therefore show synergistic effects, leading to better patient benefits $[7,10,12]$.

The primary objective of the phase I study reported here was to determine the MTD and the DLT of everolimus in combination with escalating low-dose gemcitabine. Combination treatment with everolimus and low-dose gemcitabine was well tolerated and MTD was not reached within cohorts $1-3$. In cohort 5, DLTs were observed in two patients (liver toxicity); thus, MTD was determined as $400 \mathrm{mg} / \mathrm{m}^{2} /$ week gemcitabine in combination with $5 \mathrm{mg}$ everolimus daily. These findings are consistent with safety data of other clinical trials in different tumor entities, which showed that everolimus was well tolerated even when administered in doses up to $10 \mathrm{mg}$ or in combination with low-dose chemotherapeutics [13,17,18,22,26]. Furthermore, efficacy and safety analyses were carried out in all treated patients: because of the relatively low number of patients, however, the results should be interpreted with caution. In terms of treatment efficacy, none of the patients achieved a CR, but an objective disease control was observed in the majority of patients (78\%). Thrombocytopenia was the most frequent $\mathrm{AE}$, followed by leukopenia and nausea. Reduced blood cell counts and nausea are known side effects of this kind of treatment. Thus, no new safety concerns were identified for everolimus in combination with gemcitabine, including acute and chronic toxicities in patients with advanced pancreatic cancer.

\section{Conclusion}

It may be concluded from the results of the study presented that the MTD was found to be $400 \mathrm{mg} / \mathrm{m}^{2} /$ week gemcitabine and $5 \mathrm{mg} /$ day everolimus. Overall, no new safety concerns were identified for the combination of mTOR-inhibitor everolimus and low-dose chemotherapy for locally advanced and/or metastatic pancreatic cancer. Combination treatment with $400 \mathrm{mg} / \mathrm{m}^{2} /$ week gemcitabine 
and $5 \mathrm{mg}$ /day everolimus should therefore be investigated further in clinical phase II trials in patients with advanced pancreatic adenocarcinoma.

\section{Acknowledgements}

The study was funded by Novartis Pharma GmbH, Germany. Financial support for medical editorial assistance was provided by Novartis Pharma GmbH, Germany. The authors thank Sabine Quast for their medical editorial assistance with this manuscript.

\section{Conflicts of interest}

M.J. has received travel expenses from Novartis to attend study meetings. G.V.W. has received grants for his institution from Novartis. A.K. is an employee of Novartis Pharma GmbH, Germany. C.J.B. received a consulting fee/honorarium and travel expenses form Novartis to attend study meetings. For the remaining authors there are no conflicts of interest.

\section{References}

1 Heinemann V, Haas M, Boeck S. Systemic treatment of advanced pancreatic cancer. Cancer Treat Rev 2012; 38:843-853.

2 Assifi MM, Hines OJ. Anti-angiogenic agents in pancreatic cancer: a review. Anticancer Agents Med Chem 2011; 11:464-469.

3 Davis JL, Pandalai P, Ripley RT, Langan RC, Steinberg SM, Walker M, et al. Regional chemotherapy in locally advanced pancreatic cancer: RECLAP trial. Trials 2011; 12:129.

4 Kindler HL, Niedzwiecki D, Hollis D, Sutherland S, Schrag D, Hurwitz H, et al. Gemcitabine plus bevacizumab compared with gemcitabine plus placebo in patients with advanced pancreatic cancer: phase III trial of the Cancer and Leukemia Group B (CALGB 80303). J Clin Oncol 2010; 28:3617-3622.

5 Philip PA, Benedetti J, Corless CL, Wong R, O'Reilly EM, Flynn PJ, et al. Phase III study comparing gemcitabine plus cetuximab versus gemcitabine in patients with advanced pancreatic adenocarcinoma: Southwest Oncology Group-directed intergroup trial S0205. J Clin Oncol 2010; 28:3605-3610.

6 Koido S, Homma S, Takahara A, Namiki Y, Tsukinaga S, Mitobe J, et al. Current immunotherapeutic approaches in pancreatic cancer. Clin Dev Immunol 2011; 2011:1-15.

7 Bruns CJ, Koehl GE, Guba M, Yezhelyev M, Steinbauer M, Seeliger H, et al. Rapamycin-induced endothelial cell death and tumor vessel thrombosis potentiate cytotoxic therapy against pancreatic cancer. Clin Cancer Res $2004 ; 10: 2109-2119$.

8 Cohen J. Behind the headlines of endostatin's ups and downs. Science 1999; 283:1250-1251.

9 Folkman J, Browder T, Palmblad J. Angiogenesis research: guidelines for translation to clinical application. Thromb Haemost 2001; 86:23-33.

10 Browder T, Butterfield CE, Kräling BM, Shi B, Marshall B, O'Reilly MS, Folkman J. Antiangiogenic scheduling of chemotherapy improves efficacy against experimental drug-resistant cancer. Cancer Res 2000; 60:1878-1886.

11 Bruns CJ, Harbinson MT, Davis DW, Portera CA, Tsan R, McConkey DJ, et al. Epidermal growth factor receptor blockade with $\mathrm{C} 225$ plus gemcitabine results in regression of human pancreatic carcinoma growing orthotopically in nude mice by antiangiogenic mechanism. Clin Cancer Res 2000; 6:1936-1948.

12 Sessa C, Tosi D, Viganò L, Albanell J, Hess D, Maur M, et al. Phase lb study of weekly mammalian target of rapamycin inhibitor ridaforolimus (AP23573; MK-8669) with weekly paclitaxel. Ann Oncol 2010; 21:1315-1322.

13 Wolpin BM, Hezel AF, Abrams T, Blaszkowsky LS, Meyerhardt JA, Chan JA, et al. Oral mTOR inhibitor everolimus in patients with gemcitabine-refractory metastatic pancreatic cancer. J Clin Oncol 2009; 27:193-198.

14 Grewe M, Gansauge F, Schmid RM, Adler G, Seufferlein T. Regulation of cell growth and cyclin D1 expression by the constitutively active FRAPp70s6K pathway in human pancreatic cancer cells. Cancer Res 1999; 59:3581-3587.

15 Okuno S. Mammalian target of rapamycin inhibitors in sarcomas. Curr Opin Oncol 2006; 18:360-362.

16 Tarhini A, Kotsakis A, Gooding W, Shuai Y, Petro D, Friedland D, et al. Phase Il study of everolimus (RAD001) in previously treated small cell lung cancer. Clin Cancer Res 2010; 16:5900-5907.

17 Yao JC, Phan AT, Chang DZ, Wolff RA, Hess K, Gupta S, et al. Efficacy of RAD001 (everolimus) and octreotide LAR in advanced low- to intermediategrade neuroendocrine tumors: results of a phase II study. J Clin Onco/ 2008; 26:4311-4318.

18 Yao JC, Lombard-Bohas C, Baudin E, Kvols LK, Rougier P, Ruszniewski P, et al. Daily oral everolimus activity in patients with metastatic pancreatic neuroendocrine tumors after failure of cytotoxic chemotherapy: a phase II trial. J Clin Oncol 2010; 28:69-76.

19 Hainsworth JD, Infante JR, Spigel DR, Peyton JD, Thompson DS, Lane CM, et al. Bevacizumab and everolimus in the treatment of patients with metastatic melanoma: a phase 2 trial of the Sarah Cannon Oncology Research Consortium. Cancer 2010; 116:4122-4129.

20 Richter S, Pink D, Hohenberger P, Schuette H, Casali PG, Pustowka A, et al. Multicenter, triple-arm, single-stage, phase II trial to determine the efficacy and safety of everolimus (RAD001) in patients with refractory bone or soft tissue sarcomas including GIST [abstract 10038]. J Clin Oncol 2010; 28:15s.

21 Motzer RJ, Escudier B, Oudard S, Hutson TE, Porta C, Bracarda S, et al. Efficacy of everolimus in advanced renal cell carcinoma: a double-blind, randomised, placebo-controlled phase III trial. Lancet 2008; 372:449-456.

22 Yao JC, Shah MH, Ito T, Bohas CL, Wolin EM, Van Cutsem E, et al. RAD001 in Advanced Neuroendocrine Tumors, Third Trial (RADIANT-3) Study Group. Everolimus for advanced pancreatic neuroendocrine tumors. N Engl J Med 2011; 364:514-523.

23 Baselga J, Campone M, Piccart M, Burris HA III, Rugo HS, Sahmoud T, et al. Everolimus in postmenopausal hormone-receptor-positive advanced breast cancer. N Engl J Med 2012; 336:520-529.

24 Pacey S, Rea D, Steven C, Brock C, Knowlton N, Shand N, et al. Results of a phase 1 clinical trail investigating a combination of the oral mTOR-inhibitor Everolimus (E, RAD001) and Gemcitabine (GEM) on patients (pts) with advanced cancers [abstr 3120]. J Clin Oncol 2004; 22:14s.

25 Boeck S, Jung A, Laubender RP, Neumann J, Egg R, Goritschan C, et al. EGFR pathway biomarkers in erlotinib-treated patients with advanced pancreatic cancer: translational results from the randomised, cross-over phase 3 trial AIO-PK0104. Br J Cancer 2013; 108:469-476.

26 Tuncyurek P, Mayer JM, Klug F, Dillmann S, Henne-Bruns D, Keller F, Stracke $S$. Everolimus and mycophenolate mofetil sensitize human pancreatic cancer cells to gemcitabine in vitro: a novel adjunct to standard chemotherapy? Eur Surg Res 2007; 39:380-387. 